\title{
ASSESSMENT OF WELD LINE PERFORMANCE OF PP/TALC MOLDINGS PRODUCED IN HOT RUNNER INJECTION MOULDS
}

Carolina L. Morelli / Materials Engineering Dept., Universidade Federal de São Carlos, Brazil

José Alexandrino de Sousa /Materials Engineering Dept., Universidade Federal de São Carlos, Brazil

António S. Pouzada / IPC / Institute for Polymers and Composites, University of Minho, Portugal 


\title{
ASSESSMENT OF WELD LINE PERFORMANCE OF PP/TALC MOLDINGS PRODUCED IN HOT RUNNER INJECTION MOULDS
}

Carolina L. Morelli / Materials Engineering Dept., Universidade Federal de São Carlos, Brazil José Alexandrino de Sousa /Materials Engineering Dept., Universidade Federal de São Carlos, Brazil

António S. Pouzada / IPC / Institute for Polymers and Composites, University of Minho, Portugal

\begin{abstract}
(100-200)
Weld lines are weak regions in thermoplastic injection moldings, due to low molecular entanglement and unfavorable orientation. They become more critical when particulate fillers are compounded with the polymer. The performance of weld lines in talc filled polypropylene box moldings produced with a double gated hot runner mold was assessed. The processing conditions were varied in order to cause morphology and tensile-impact resistance changes. The weld performance at room temperature was assessed in terms of the energy absorbed in the impact tests. It was found that it depends on the injection temperature, the injection rate, and on the orientation of the talc particles in the weld line plane.
\end{abstract}




\section{ASSESSMENT OF WELD LINE PERFORMANCE OF PP/TALC MOLDINGS PRODUCED IN HOT RUNNER INJECTION MOULDS}

Carolina L. Morelli / Materials Engineering Dept., Universidade Federal de São Carlos, Brazil José Alexandrino de Sousa /Materials Engineering Dept., Universidade Federal de São Carlos, Brazil

António S. Pouzada / IPC / Institute for Polymers and Composites, University of Minho, Portugal

\section{Key words}

Injection molding, polypropylene, talc, weld lines. 


\section{Background}

Composites of polypropylene with talc have a broad spectrum of applications due to their good combination of mechanical properties, ease of molding and low cost. Injection molding is commonly used to process these composites.

In many injection molded parts, when two melt streams meet each other during the processing, a weld line is formed. When the meeting involving two flows coming from opposite sides is frontal and without additional flow, a cold or butt weld line is formed with lower mechanical strength. If the stream meeting is lateral and the fronts have still some time to flow together and under pressure inside the impression the resulting hot or streaming weld line is stronger than the previous one [1].

A weld line is a region of low mechanical strength of the part due to: a) unfavorable molecular orientation, b) insufficient bonding (due to insufficient entanglements), and c) formation of a V-notch that works as a stress concentrator [2]. In the case of composites, the presence of a weld line is more critical because the fillers tend to be oriented in the weak plane of the weld line. In cold weld lines the molecular entanglement is worse and the filler orientation in the weld line plane is perpendicular to the direction of mechanical loading of the part. Even with lamellar fillers such as talc, which have low aspect ratio, there is also a preferential orientation in the plane of the weld line.

Upon changing the processing parameters it is possible to improve the weld line resistance. This can be achieved through the improvement of the molecular cohesion in the weld line region, the rise of the molecular or filler orientation in the direction of mechanical loading, or the development of a favorable crystalline structure [2 - 5].

In composite materials the molding morphology and the subsequent mechanical performance are influenced by the presence of the filler. In the case of talc, authors as Alonso et al. [6] reported a nucleation effect on the crystallization of the polymer matrices. Other authors, as Zipper et al. [7], 
verified that the presence of talc increases the preferential orientation of the crystalline domains of the matrix.

The properties of a material in a part are directly related to its morphology. The morphology is determined by the intrinsic characteristics of the material and by the processing set up. It is well known that during the injection molding, and because of the developed stress rate and velocity profiles, a skincore structure is formed across the thickness of the part. The skin is the highly oriented structure developed near the mould surfaces, where the shear rate is higher. The core of the molding, away from the cold mould surfaces, is a non-oriented spherulitic region. The degree of crystallinity, the skin/core ratio and the overall structure are influenced by the processing conditions [8]. In the presence of a weld line, which is a macro-defect inside the molding and is also affected by the processing parameters, additional aspects concerning to the mechanical behavior of the part must be considered. The influence of injection temperature $\left(\mathrm{T}_{\mathrm{i}}\right)$ and injection time $\left(\mathrm{t}_{\mathrm{i}}\right)$ in the morphology of moldings have been analyzed $[9,10]:$

- $\quad$ The increase in $\mathrm{T}_{\underline{i}}$ leads to a less oriented structure, reflected by the decrease of the skin thickness, because of the higher energy supplied and the longer time before freezing. Thus, more relaxation of the molecules and recovery of the deformation induced during the cavity filling can happen. In semicrystalline polymers the raise of $T_{i}$ induces the increase of the crystalline fraction and the formation of larger spherulites in the core. A high $\mathrm{T}_{\mathrm{i}}$ also leads to a lower viscosity, hence to a higher molecular mobility in the melt, which benefits the chain entanglement when weld lines occur.

- The increase in injection time $t_{i}$ (or decrease in injection rate) is also reflected in the part in two “competitive" ways with regard to the final mechanical performance. On one hand there is a decrease of the shear rate leading to the formation of a less oriented structure. On the other, there is less heating generated by viscous dissipation in comparison with higher shearing conditions, which allows the freezing of the induced orientation. 
Previous works $[8,11]$ have demonstrated that the increase of the skin layer thickness leads to an improvement in the modulus of the material, since there are more molecules oriented in the direction of the applied force. This higher orientation is reflected in an increase of the resistance of the material to deformation, especially when this deformation is imposed at high strain rates, as in impact tests. Thus, a thicker skin layer must result in a reduced impact resistance of the material, which is consistent with the results reported by Karger-Kocsis et al. [11].

\section{Experimental}

This study was carried out using a copolymer of propylene-ethylene, $\mathrm{PP}_{\text {cop }}$ - PX 1995 (from Braskem, Brazil) with melt flow rate of 4,71 g/10min) and a talc filler, T - GM-10 (from Magnesita, Brazil, with average particle size of $d_{50}=2,60 \mu \mathrm{m}$, as measured by sedigraphy, and aspect ratio of 2,8).

The talc composites, with 20 and 30\% in weight of talc (20T and 30T, respectively), were prepared in a Werner-Pfleiderer ZSK-30 co-rotating twin-screw extruder.

Rectangular boxes of 1.4 mm thickness, shown in Figure 1, were injection molded in a double-gated hot runner injection mould, using a Klöckner Ferromatic FM20 injection machine of $200 \mathrm{kN}$ clamping force. The following settings were used for producing the moldings:

- $\quad$ Injection temperature $\left(\mathrm{T}_{\mathrm{i}}\right): 210^{\circ} \mathrm{C}$ and $250{ }^{\circ} \mathrm{C}$;

- $\quad$ Injection time $\left(\mathrm{t}_{\mathrm{i}}\right): 1 \mathrm{~s}$ and $2 \mathrm{~s}$;

- $\quad$ Mould temperature: $40^{\circ} \mathrm{C}$;

- $\quad$ Holding pressure $\left(\mathrm{p}_{2}\right)=70 \%$ of the injection pressure $\left(\mathrm{p}_{1}\right)$.

Tensile-impact tests were carried out at room temperature using a Ceast hammer of 7.5 J. For these tests, dog-bone shaped samples with transversal area of $4 \times 1.4 \mathrm{~mm}^{2}$ were cut at different locations in the box, along the region of weld line formation (wc, wm, we and $w l$ ) and away from the weld line, in a radial position along the flow direction $(R)$, as shown in Figure 2. In spite of the symmetry of the molding the formed weld line was not straight, due to a slight unbalance of the two injection gates. 
Therefore, the location of the samples for the tensile-impact tests was chosen so that specimens with variable properties could be obtained. These properties were expected to vary from a maximum, $R$, (in the flow direction and without weld line) to values that depend on the packing pressure and the inclination of the weld line with respect to the specimen axis (wc, with a perpendicular weld line plane and the maximum packing pressure, to $w l$, with an inclined weld line and the minimum packing pressure).

Polarized light microscopy was used to observe the morphology of the unfilled $\mathrm{PP}_{\text {cop }}$ moldings resulted from the processing parameters. For this analysis, $15 \mu \mathrm{m}$ thick specimens were microtomed with a Leitz 1401 microtome and observed with an Olympus BH2 polarized light microscope.

The fractured surfaces of the tensile-impact test-specimen were viewed by Scanning Electron Microscopy (SEM) to analyze the probable fracture initiation zones and the overall fracture behaviour. For this, a Leica Cambridge Microscopy, model S360, was used and the samples were covered with a thin gold layer. Samples were also cryo-fractured after immersion in liquid nitrogen in the direction transverse to the thickness and analyzed by SEM to verify the talc particles orientation along the molding thickness. The planes studied in each analysis are shown in Figure 3.

The commercial software Moldflow Plastic Insight (MPI from Moldflow Pty) was used to simulate the filling process. Thermal and rheological properties of the materials were implemented into the software database.

\section{Results and Discussions}

\section{Polarized Light Microscopy - Morphology}

The structure of the moldings obtained with different injection conditions was observed by polarized light microscopy as shown in Figure 4. 
Near the cold mold surface a frozen layer is formed followed by a shish kebab structure developed probably in the region of highest shear rate. The shish-kebab structure is common in PP and other polyolefins and is a consequence of the fast crystallization of the polymer chains under big stresses, near the skin region, already reported by Stern et al. [10].

In the vicinity of this sheared layer, $\beta$-spherulites can be found as a result of the crystallization under shear. In the core, as expected, $\alpha$-spherulites are formed under quiescent crystallization conditions.

It is possible to observe the decrease of the skin thickness with the increase in $T_{i}$. It can be also verified a smooth decrease in the skin thickness with the decrease in $t_{i}$, meaning that the effect of viscous heating was predominant to relax the oriented structure formed. The reduction in skin thickness resulting from the shortening of $t_{i}$ is more pronounced when $T_{i}$ was lower $\left(210^{\circ} \mathrm{C}\right)$. The position of the sample and its distance to the injection points also influence the morphology. Thus, it can be verified a reduction in skin thickness of samples $w l$, away from the injection gates, when compared with $w c$ and $R$.

The morphology of the $\mathrm{PP}_{\text {cop }}$ /talc composites should show the same features, because the presence of these fillers enhances the original orientation of the crystalline domains [7] and acts as a nucleant agent of the polymer crystalline structures.

\section{Tensile-impact test results}

\section{Influence of the weld line position}

The tensile-impact resistance of the moldings at the positions shown in Fig. 2 and at room temperature, in the weld line and away from it, is depicted in Fig. 5. The values are presented as $\mathrm{J} / \mathrm{m}^{2}$ to consider the transversal area over which the tension was applied. All the samples molded with the several injection conditions used showed similar trends of the impact resistance with the position in the box. Average data from these tests are presented in Figure 5. 
It is possible to observe that the toughness decreases with the increment of talc content. This was expected since the rigid particles of talc act as irregularities in the continuous matrix. The decrease in the tensile-impact resistance is more pronounced when a weld line is present. This is a consequence of: 1) lower molecular mobility and chain entanglement in the weld line, because of the viscosity increment resulting from the talc addition; 2) unfavorable orientation of the talc particles in the weld line plane.

In the Figure 5 it is also possible to verify that, for the talc filled composites, there is a trend of the impact resistance to increase from a minimum associated to the sample $w c$, where there is a frontal meeting of the flow fronts, to $R$, the reference sample in a location well away from the weld line. This trend may result both from geometrical aspects of the part and from the filling process of the molding. It was already mentioned that the weld line was not straight. Nevertheless it can be observed that the inclination of the weld line plane with respect to the specimen axis varies from a maximum of $90^{\circ}$ (sample $w c$ ) to a minimum around $45^{\circ}$ (sample $w l$ ), at the side wall of the molding. Therefore, at the region wc the polymer chains and the fillers are oriented in a plane transversal to the applied force , contributing to the weakness of this sample. In the other regions ( $w m$, we and $w l$ ), the weld line formed is not exactly transversal to the tensile imposed, what attenuates the depreciative effect of the weld line. The talc composite samples at the location $R$ show the best performance due to the absence of the weld line.

\section{Influence of the talc filling}

In the case of the pure polymer, due to the high ductility of the $\mathrm{PP}_{\text {cop }}$ at room temperature, the tensileimpact test without notch does not discriminate samples with and without weld line nor is sensitive to the various locations on the box or the injection molding conditions.

The tensile-impact resistance data summarized in the Figure 5 can be normalized using a weld line depreciation factor $\left(\mathrm{F}_{\mathrm{WL}}\right)$ given by the following equation. 


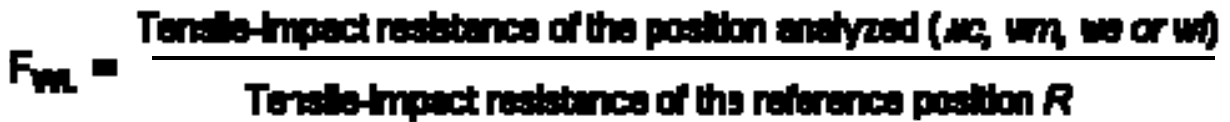

The result of the normalization is shown in Figure 6. Lower values of the $F_{\mathrm{WL}}$ indicate a more severe depreciation effect of the weld line and the consequent decrease in the mechanical property analyzed.

The data referring to the unfilled moldings suggest an unexpected depreciation factor, $\mathrm{F}_{\mathrm{WL}}$, close or higher than 1. The first inference is that, as mentioned before, the failure mechanism of theses samples was not controlled by the weld line. In fact it was observed a large scale whitening of the samples corresponding to a macroscale deformation of the samples upon impact. Thus, the enhanced mechanical performance should be associated to other morphological parameters already evident in Figure 4. Being known that the skin is always a region of higher stiffness, one would expect a reduced toughness from larger skin samples. This fact is observed with the $\mathrm{PP}_{\text {cop }}$ samples $w c$ and $R$, that display a larger skin ratio, while in samples $w m$, we and $w l$ the skin thickness was smaller.

In the case of the talc filled composites, the lower values of $\mathrm{F}_{\mathrm{WL}}$ were found with the sample wc (transversal plane of weld line), indicating the worse detrimental effect of the weld line in the tensileimpact resistance when it is perpendicular to the impact direction. This is a consequence of: (a) the orientation of the talc particles in the plane of the weld line, unfavorable to the direction of mechanical loading; (b) the higher melt viscosity of the composites with 20 and $30 \mathrm{wt} \%$ of talc that decreases the molecular mobility, the chain entanglement and the healing of the weld line.

\section{Influence of the processing conditions}

For analyzing the effect of processing conditions in the weld line effect the sample wc was chosen, for its more critical position and poorest weld resistance. The tensile-impact data obtained with $20 \%$ and $30 \%$ talc filled composites using two injection temperatures $\left(210^{\circ} \mathrm{C}\right.$ and $\left.250^{\circ} \mathrm{C}\right)$ and two injection times (1 and 2 s) are depicted in Figure 7 and Table 1. 
With the lowest injection temperature $\left(T_{i}=210^{\circ} \mathrm{C}\right)$, there is a visible influence of the injection rate (or injection time) in the toughness of the composites. This is more evident for the less filled materials which in turn are more impact resistant. Shorter $t_{i}(1 \mathrm{~s})$ led to higher bulk temperature $\left(T_{b}\right)$ and longer time to freeze-off $\left(t_{f}\right)$, as could be confirmed by the Moldflow simulation data in Table 2, due to the viscous heating generated. Thus, more energy is available to the macromolecules, increasing their mobility, and there is also more time to the formation of entanglements in the weld line region.

At higher molding temperature $\left(\mathrm{T}_{\mathrm{i}}=250^{\circ} \mathrm{C}\right)$ a trend with respect to the toughness (increase or decrease) could not be noted with the variation of the injection rate applied (1 or $2 \mathrm{~s}$ ) .

In the case of pure, or unfilled, $\mathrm{PP}_{\mathrm{cop}}$ the assessment of the weld line performance can not be made using test data gathered at room temperature. At this temperature the ductile characteristics of the material prevails and the weld line is not determinant in the toughness of the moldings. This means that at the room temperature the tensile-impact test is not able to discriminate the influence of the weld line in the product performance, if its quality is significantly good as the case of the unfilled $\mathrm{PP}_{\text {cop. }}$ In all samples taken from the box of $\mathrm{PP}_{\text {cop }}$ material and in all injection conditions analyzed the fracture was ductile and the tensile-impact results were similar. The influence of the weld lines in the toughness in this case suggests resort to sub-zero temperature testing, well below the glass transition temperature of the polymer.

\section{Scanning Electron Microscopy}

Micrographs of cryo-fractured composite samples surfaces in the plane transverse to the molding thickness are shown in Figure 8.

Differences in the talc particles orientation can be observed across the molding thickness. As a consequence of the fountain flow effect and relatively lower mould surface temperatures, the lamellae of talc particles and the polymer melt flow are frozen close to the surface (skin) with an orientation 
favorable to the mechanical loading, while the core maintains the predominantly transverse orientation. In the plane of weld line, where the two fronts coming from opposite sides meet each other, the orientation of the frozen polymer melt and of the lamellae of talc must be perpendicular to the direction of filling along all the thickness extension.

The fracture-surface photographs of the tensile-impact test specimen of the composites with 30\%wt of talc are shown in Figure 9. Analyzing the photographs starting from the sample $R$, without weld line, to the sample $w c$, with the most critical and evident weld line, it is possible to verify the transition from ductile (deformed surface) to brittle (smooth surface) fracture behavior.

A central mark in the core region of the samples shown in Figure 9 can be clearly observed on the tensile-impact fracture surfaces, which appears to project outwards or inwards, depending on the half of the test specimen part analyzed (there is a symmetry). This central region probably indicates the location of fracture initiation in the tensile-impact test specimen. This would be expected, once in this region there is an unfavorable orientation (transverse to the mechanical loading) of the talc lamellae and of the polymer chains, and also due to a stress state created during the differential cooling of the moulded part, as explained next.

When the filling of the part ends, there is a solidified outer layer (skin) of polymer encasing the molten core. The skin is much stiffer than the core and prevents the core shrinkage. The net result is that the skin receives a compression force by the contraction of the core, and the core becomes extended by the restraint of the skin until stress equilibrium is reached. This so-called free quench cooling induces a parabolic residual stress distribution in the molding with a compressive stress in the plane on the surface and hydrostatic tension inside, with a resultant stress of zero to realize equilibrium, as commented by Powell and Housz [12]. 
It can also be seen in the sample wc flat surfaces in the regions near to the mould wall (skin), indicating a brittle fracture that could also be responsible for the initiation of the fracture. This behavior is a consequence of the fountain flow considering that, in the case of a butt weld line like was formed here, the flow fronts first meet in the centre. In the extremities the molecular entanglement is deficient and the differential shrinkage trend to form a V-notch on the surface, which concentrates the tension and induces the fracture. The scheme showed in Figure 10 represents qualitatively what probably happened to the sample wc.

\section{Conclusions}

The impact strength of talc filled polypropylene composites is influenced by the filler content and the processing conditions that affect orientation (injection temperature and injection rate). The influence of the weld lines in the toughness of PP/talc composite moldings can be assessed by tensile-impact tests on samples punched off from the moldings at room temperature. The tensile-impact strength of the weld lines depends on the injection temperature and the injection rate, the influence of the latter being more pronounced at lower injection temperatures. Nevertheless the main factor influencing the tensile-impact resistance is the orientation of the talc particles in the weld line plane.

\section{Acknowledgments}

The authors acknowledge the support given by the EU programme ALFA through the network PLASTINET, and also by the companies Borealis Brazil S.A., Magnesita S.A. and Vetrotex /SaintGobain for the supply of their materials. 


\section{References}

[1] T. Nguyen-Chung, Rheol Acta, 43, 240 (2004).

[2] R. Seldén, Polym. Eng. and Science, 37, 205 (1997).

[3] T.Tjader, J.Seppala and P.Jaasjelainen, J. Materials Science, 33, 923 (1998).

[4] J.K. Kim, J.H. Song, S.T. Chung and T.H. Kwon, Polym. Eng. and Science, 37, 228 (1997).

[5] O.G.Ersoy and N.Nugay, Polymer, 45, 1243 (2004).

[6] M. Alonso, J.I. Velasco and J.A. Saja, Eur. Polym. J., 33, 255 (1997).

[7] P. Zipper, B. Chernev, K. Schnetzinger and K. Lederer, Proceedings of 18th PPS Ann Meeting, (2001).

[8] J.C. Viana, A.M. Cunha and N. Billon, J. Materials Science, 36, 4411 (2001).

[9] A.M. Cunha and A.S. Pouzada, Plast,. Rubb. and Comp. Process. and Appl., 18, 79 (1992).

[10] C. Stern, A.R. Frick, G. Weickert, G.H. Michler and S. Henning, Macromol. Mater. Eng., 290, 621 (2005).

[11] J. Karger-Kocsis, D.E. Mouzakis, G.W. Ehrenstein and J. Varga, J. Appl. Polym. Sci., 73, 1205 (1999).

[12] P.C. Powell and A.J.I. Housz, Engineering with polymers, Stanley Thornes Publishers Ltd (1998). 
Table 1 - Tensile-Impact resistance of the sample wc using different molding conditions

\begin{tabular}{|c|c|c|c|c|}
\hline \multicolumn{5}{|c|}{ Tensile-Impact Resistance $\left(10^{5} \mathrm{~J}^{\prime} \mathrm{m}^{2}\right)$} \\
\hline $\mathrm{T}_{\mathrm{i}} \rightarrow$ & \multicolumn{2}{|c|}{$210^{\circ} \mathrm{C}$} & \multicolumn{2}{c|}{$250^{\circ} \mathrm{C}$} \\
\hline $\mathrm{t}_{\mathrm{i}} \rightarrow$ & $1 \mathrm{~s}$ & $2 \mathrm{~s}$ & $1 \mathrm{~s}$ & $2 \mathrm{~s}$ \\
\hline $\mathrm{PP}_{\text {cop }}$ & 5,17 & 4,75 & 5,52 & 5,60 \\
\hline $20 \mathrm{~T}$ & 2,39 & 1,70 & 2,26 & 2,06 \\
\hline $30 \mathrm{~T}$ & 2,04 & 1,64 & 1,68 & 1,70 \\
\hline
\end{tabular}


Table 2- Bulk Temperature and Time to Freeze simulated using Moldflow ${ }^{\circledR}$.

\begin{tabular}{|c|c|c|c|}
\hline \multicolumn{4}{|c|}{ Bulk Temperature $\mathrm{T}_{\mathrm{b}}\left({ }^{\circ} \mathrm{C}\right)$} \\
\hline $\begin{array}{c}\mathrm{T}_{\mathrm{i}} \\
\left({ }^{\circ} \mathrm{C}\right)\end{array}$ & $\begin{array}{c}\mathrm{t}_{\mathrm{i}} \\
(\mathrm{s})\end{array}$ & $\mathrm{PP}_{\mathrm{cop}}$ & $30 \mathrm{~T}$ \\
\hline \multirow{2}{*}{210} & 1 & 180,2 & 180,3 \\
\cline { 2 - 4 } & 2 & 147,3 & 148,6 \\
\hline \multirow{2}{*}{250} & 1 & 208,7 & 208,0 \\
\cline { 2 - 4 } & 2 & 166,5 & 167,4 \\
\hline
\end{tabular}

\begin{tabular}{|c|c|c|c|}
\hline \multicolumn{4}{|c|}{ Time to freeze $\mathrm{t}_{\mathrm{f}}(\mathrm{s})$} \\
\hline $\begin{array}{c}\mathrm{T}_{\mathrm{i}} \\
\left({ }^{\circ} \mathrm{C}\right)\end{array}$ & $\begin{array}{c}\mathrm{t}_{\mathrm{i}} \\
(\mathrm{s})\end{array}$ & $\mathrm{PP}_{\mathrm{cop}}$ & $30 \mathrm{~T}$ \\
\hline \multirow{2}{*}{210} & 1 & 2,91 & 2,91 \\
\cline { 2 - 4 } & 2 & 1,91 & 1,91 \\
\hline \multirow{2}{*}{250} & 1 & 3,41 & 3,41 \\
\cline { 2 - 4 } & 2 & 2,41 & 2,41 \\
\hline
\end{tabular}




\section{List of captions}

Figure 1 - The molding and test pieces for tensile impact testing.

Figure 2 - Location of the $50 \mathrm{~mm}$ long tensile-impact test specimens and position of the weld line (--).

Figure 3 - Planes observed by SEM: a) cryo-fractured samples and b) fractured surfaces of the tensile-impact test-specimen.

Figure 4 - Morphology of PPcop observed by polarized light microscopy: (I)Through thickness morphology showing the skin-core structure; (II) Detail of the morphology; (III) View of the skin structure formed at different injection conditions and locations (a) $210^{\circ} \mathrm{C} / 2 \mathrm{~s}$, (b) $210^{\circ} \mathrm{C} / 1 \mathrm{~s}$, (c) $250^{\circ} \mathrm{C} / 1 \mathrm{~s}$, (d) $250^{\circ} \mathrm{C} / 2 \mathrm{~s}$.

Figure 5 - Tensile-impact resistance of the samples at different positions in the molding.

Figure 6 - Weld line depreciation factor for the tensile-impact resistance.

Figure 7 - Tensile-impact resistance at the wc region for different materials and processing conditions.

Figure 8 - Micrographs of the cryo-fractured sample surfaces of PPcop $/ 20 \%$ talc, injected at $\mathrm{T}_{\mathrm{i}}=210^{\circ} \mathrm{C}$ and $\mathrm{t}_{\mathrm{i}}=$ 2s, showing regions of the skin (a) and the core (b). The arrows indicate the direction of flow.

Figure 9 - Fractured surfaces of samples of $30 \mathrm{~T}$ extracted from different positions of the box injected with $\mathrm{T}_{\mathrm{i}}=$ $250 \mathrm{oC}$ and $\mathrm{t}_{\mathrm{i}}=2 \mathrm{~s}$.

Figure 10 - Stresses actuating on the sample wc: a) residual stresses from the differential shrinkage during the injection molding; b) applied stress during the tensile-impact test showing the effect of tension magnification of the superficial V-notch; c) resulting stress indicating the probable regions of to the fracture initiation (arrows). 
Figures 
Morelli, Fig 1

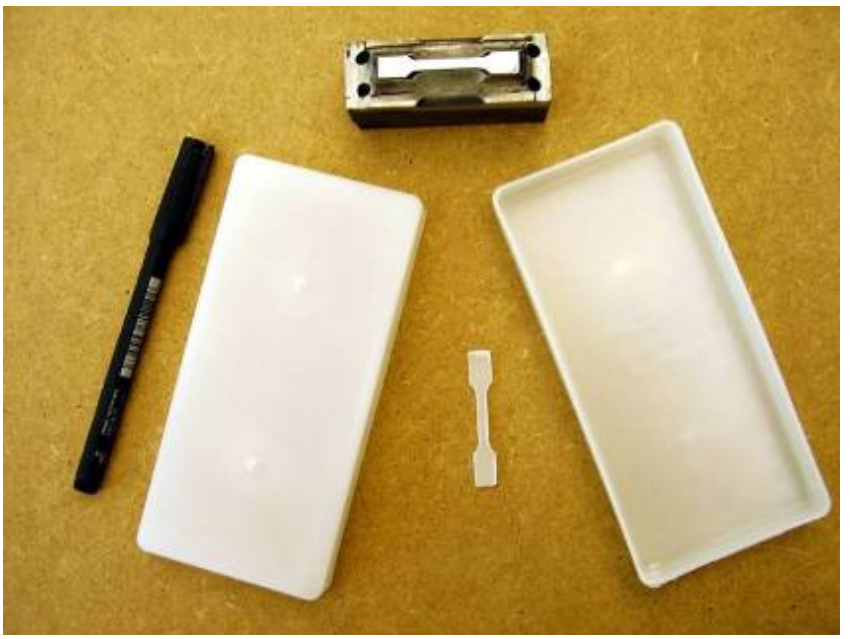


Morelli, Fig 2

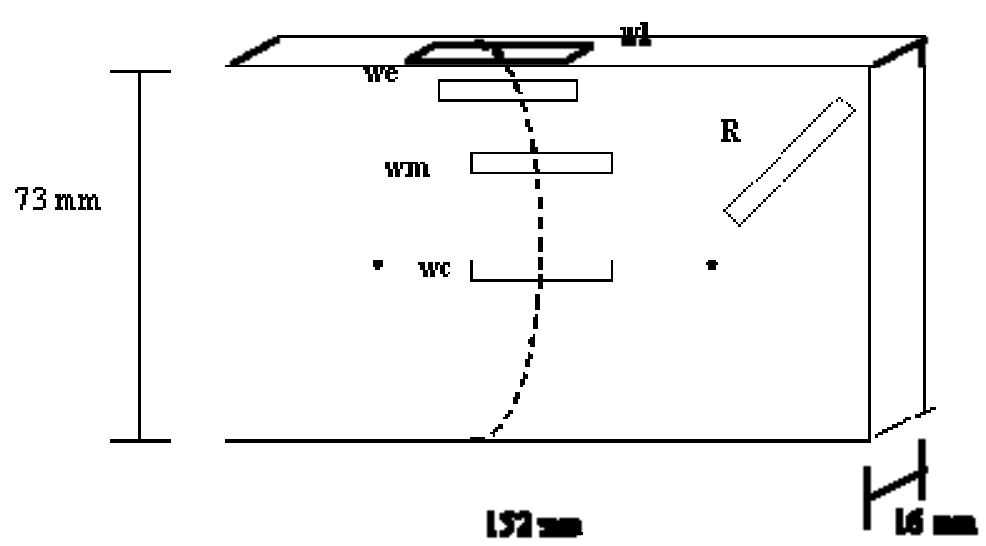


$\downarrow$

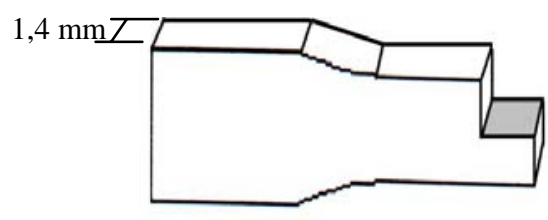

a)
Morelli, Fig 3

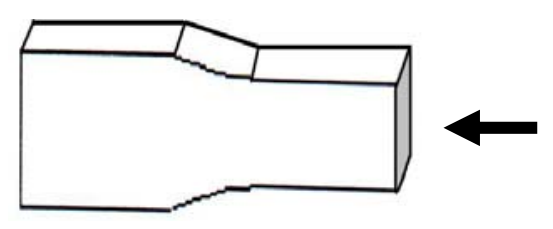

b) 
Morelli, Fig 4
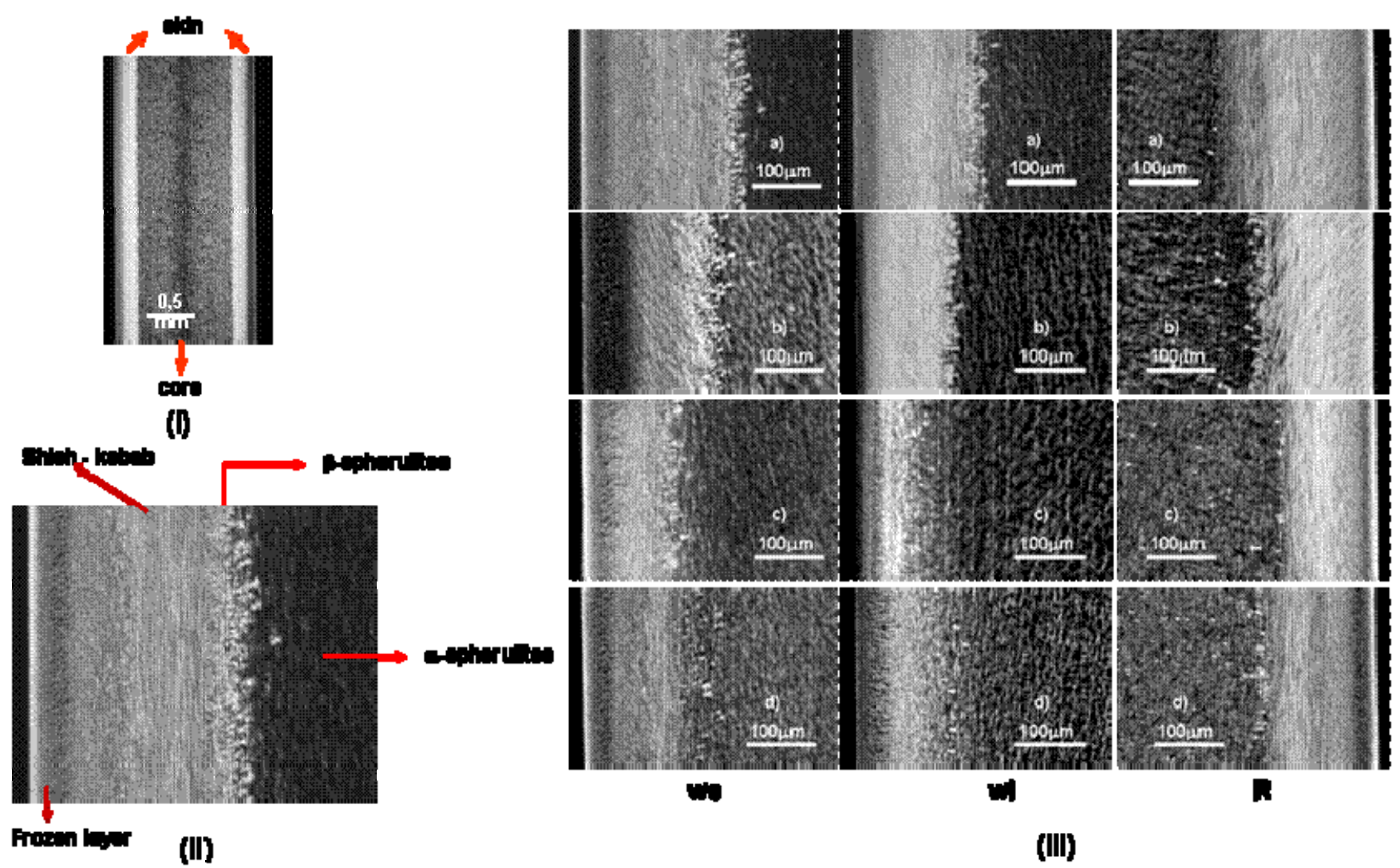

wo

w

R

(III) 
Morelli, Fig 5

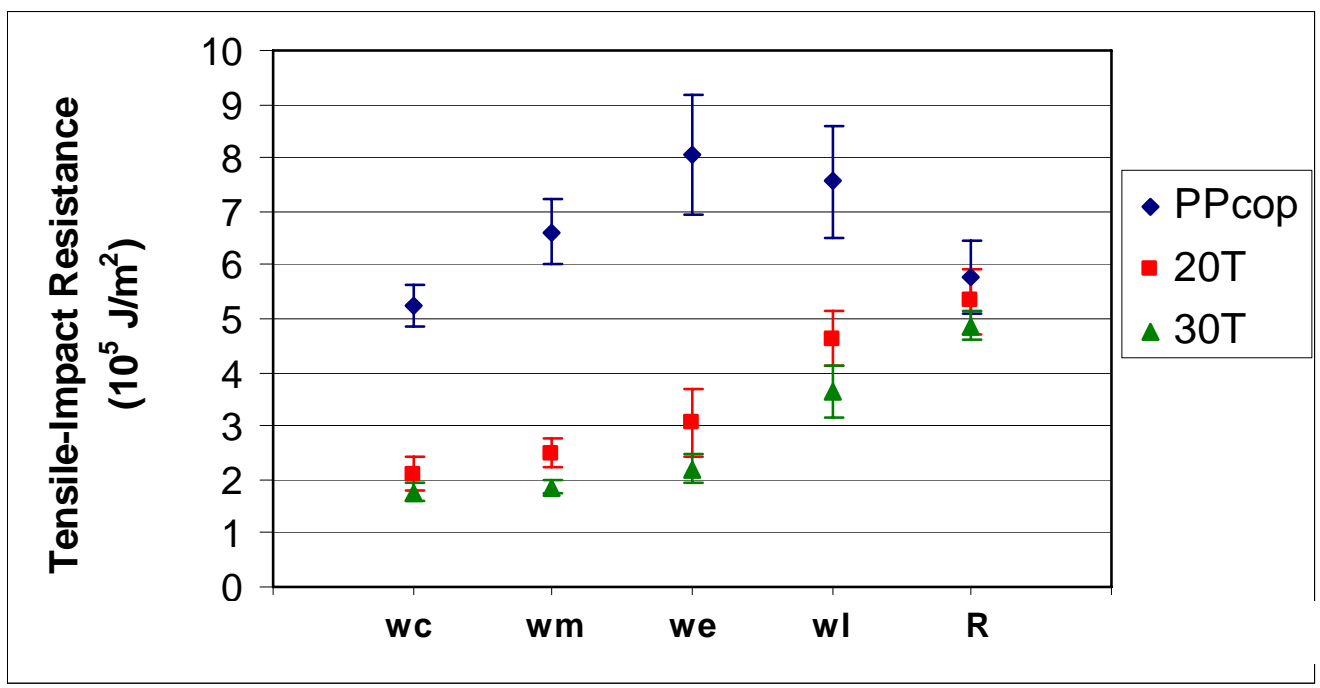


Morelli, Fig 6

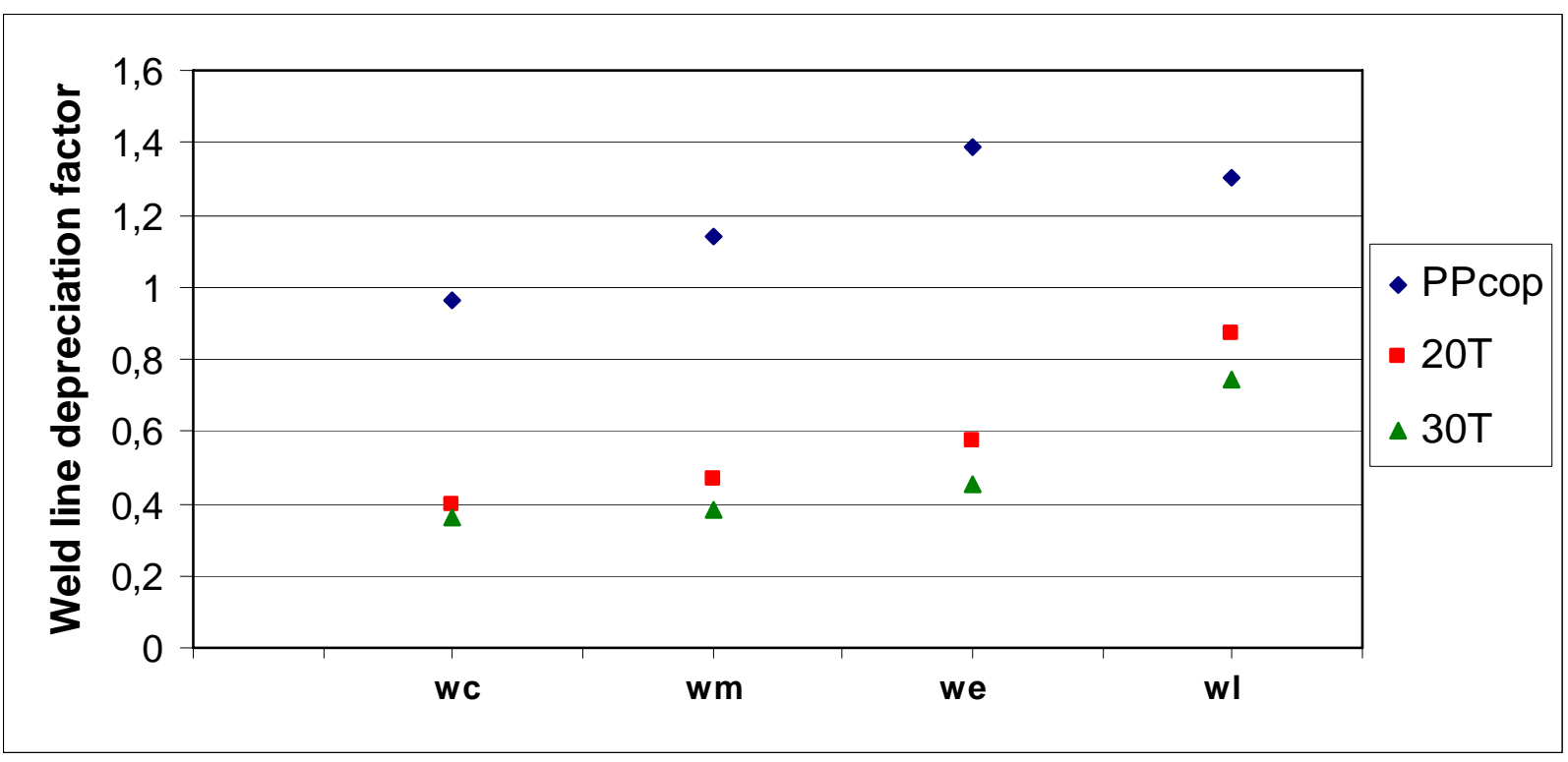


Morelli, Fig 71

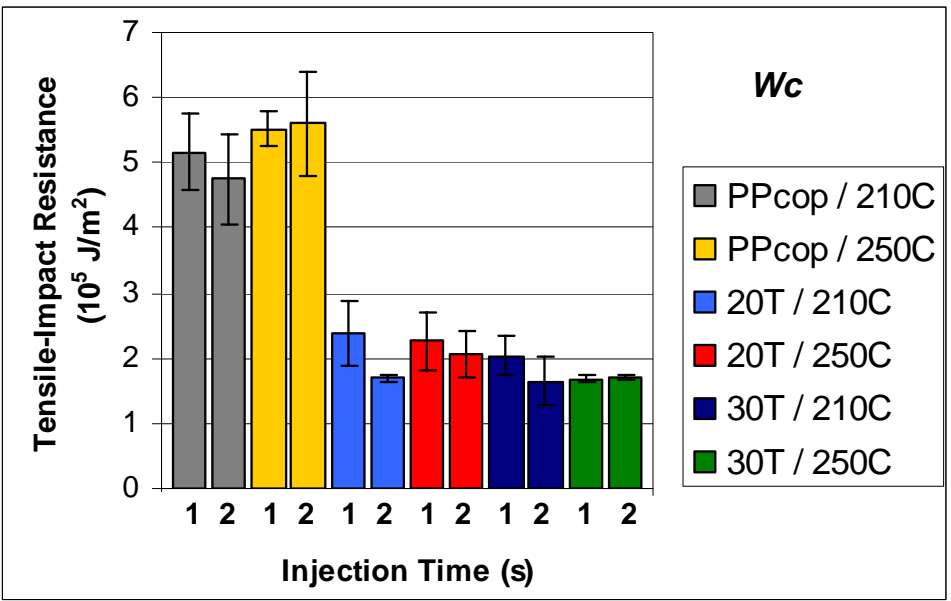


Morelli, Fig 8

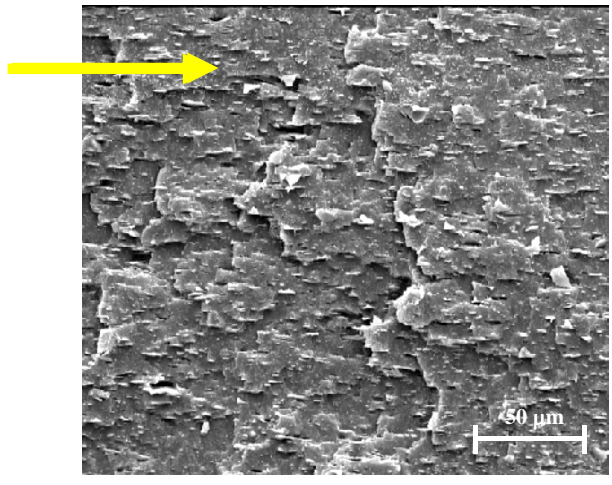

a)

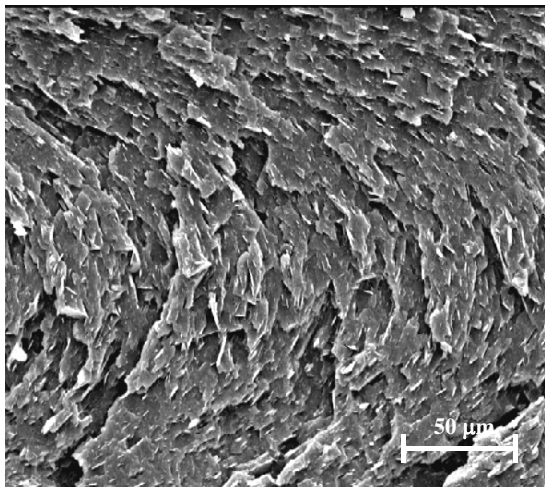

b) 
Morelli, Fig 9
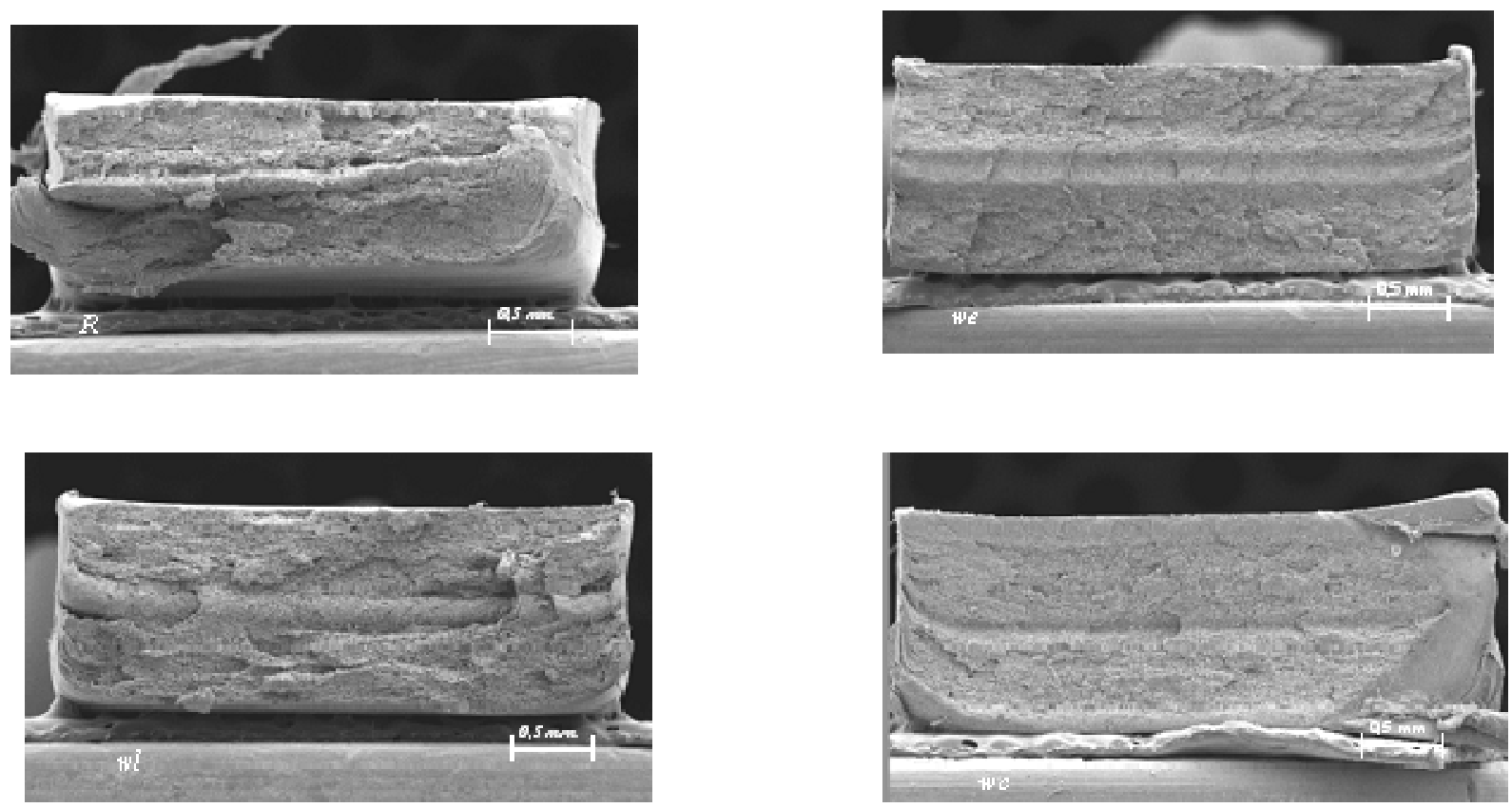
Morelli, Fig 10

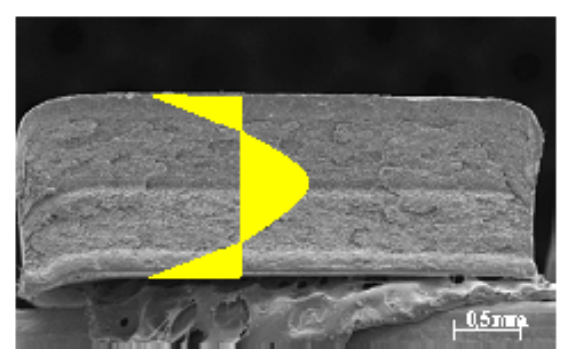

a)

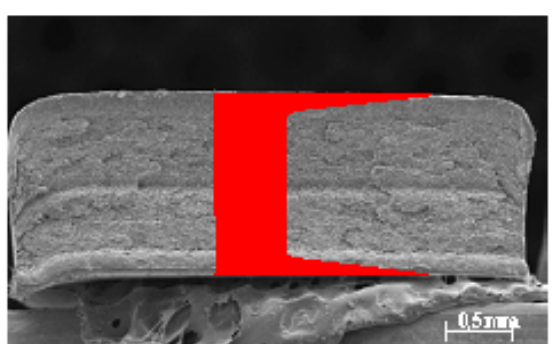

b)

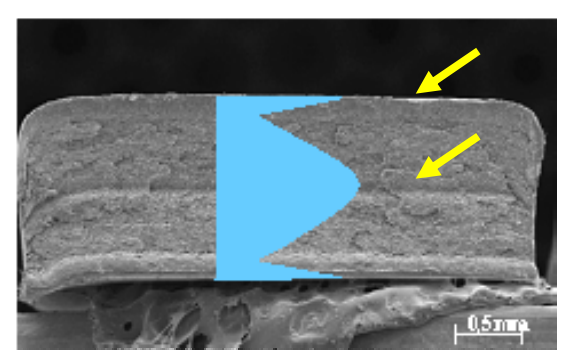

c) 